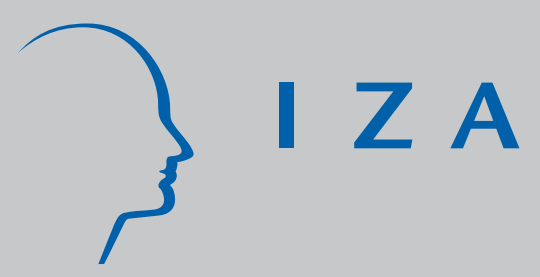

IZA DP No. 2878

Birth Spacing, Fertility Selection and Child Survival: Analysis Using a Correlated Hazard Model

Pushkar Maitra

Sarmistha Pal

J une 2007 


\title{
Birth Spacing, Fertility Selection and Child Survival: Analysis Using a Correlated Hazard Model
}

\author{
Pushkar Maitra \\ Monash University
}

Sarmistha Pal

Brunel University and IZA

Discussion Paper No. 2878

June 2007

IZA
P.O. Box 7240
53072 Bonn
Germany

Phone: +49-228-3894-0

Fax: +49-228-3894-180

E-mail: iza@iza.org

Any opinions expressed here are those of the author(s) and not those of the institute. Research disseminated by IZA may include views on policy, but the institute itself takes no institutional policy positions.

The Institute for the Study of Labor (IZA) in Bonn is a local and virtual international research center and a place of communication between science, politics and business. IZA is an independent nonprofit company supported by Deutsche Post World Net. The center is associated with the University of Bonn and offers a stimulating research environment through its research networks, research support, and visitors and doctoral programs. IZA engages in (i) original and internationally competitive research in all fields of labor economics, (ii) development of policy concepts, and (iii) dissemination of research results and concepts to the interested public.

IZA Discussion Papers often represent preliminary work and are circulated to encourage discussion. Citation of such a paper should account for its provisional character. A revised version may be available directly from the author. 


\section{ABSTRACT \\ Birth Spacing, Fertility Selection and Child Survival: Analysis Using a Correlated Hazard Model ${ }^{*}$}

If fertility reflects the choice of households, results of their choice (duration between successive births and health of the children) cannot be considered to be randomly determined. While most existing studies of child health tend to overlook the effects of fertility selection on child health, this paper argues that not accounting for this selection issue yields biased estimates. Additionally it is difficult to a priori predict the direction of this bias, thereby over or under estimating the effect of spacing on child survival. We find that the estimates of birth spacing on child mortality are different when we do not account for fertility selection. Additionally the correlated hazard estimates that we present here better fit our samples than the corresponding bivariate probit estimates used in the literature. A comparison of the fertility behaviour of households in the Indian and Pakistani Punjab highlights the differential nature of institutions on demographic transition in these neighbouring regions.

JEL Classification: J13, O10, C41, C24

Keywords: child mortality, fertility selection, correlated recursive hazard system

Corresponding author:

Sarmistha Pal

Department of Economics and Finance

Brunel University

Uxbridge UB8 3PH

United Kingdom

E-mail: sarmistha.pal@brunel.ac.uk

\footnotetext{
*Funding provided by a Faculty Research Grant Scheme, Monash University and the Cardiff Business School. The first version of this paper was written when Sarmistha Pal was based in Cardiff. We would like to thank two anonymous referees, John Cleland, Yvonne Dunlop, John Hunter, Brett Inder and Gerry Makepeace for their comments and suggestions on earlier versions of the paper. The usual caveat applies.
} 


\section{Birth Spacing, Fertility Selection and Child Survival: Analysis using a Correlated Hazard Model}

\section{Introduction}

Most existing studies tend to assume that the composition of the population of children classified by health is unrelated to prior fertility decisions. ${ }^{1}$ There are however important reasons as to why we should explicitly incorporate fertility decisions when examining child health (or child quality). Resource constrained households care about current income and hence might choose to have more children and this will be reflected in shorter duration between successive children. However the greater the number of children the household has (or the shorter the duration between successive children), the less is the amount of household resources ${ }^{2}$ that the household can devote to each child and hence the lower will be the quality of each child. Fertility and child quality (e.g., health) decisions are therefore closely intertwined and this in turn implies that we need to correct for the selection effects of fertility while studying the effects of fertility on child mortality.

This paper builds on Pitt (1997) to examine the effects of fertility selection on child mortality in the Indian sub-continent. ${ }^{3}$ In particular, we examine the effects of birth spacing on child mortality where both spacing and mortality are modelled as hazard functions (and not binary variables) and in doing so we take account of the selective nature of spacing/fertility decisions by parents. Not accounting for this selection issue leads to a potential selection bias and it is difficult a priori to predict the direction of this bias. If

\footnotetext{
${ }^{1}$ One notable exception is Makepeace and Pal (2007), who examine the effects of siblings on child mortality in a sequential framework and in doing so they allow for the endogeneity in the effects of prior and posterior siblings on child mortality.

${ }^{2}$ This not only refers to parental financial resources, but also the time and energy devoted to the care of the newborn, especially by the mother (e.g., breastfeeding). A part of the resource constraint may thus relate to the extent of maternal depletion attributable not only to shorter birth spacing but also the woman's deficiency of essential nutrients common among resource-constrained households in low income regions.

${ }^{3}$ In his paper Pitt (1997) examined the effect of maternal education on child health after explicitly accounting for fertility selection. He finds that not accounting for fertility selection results in an under-estimation of the effect of schooling in reducing child mortality.
} 
parents are less likely to have a child when its inherent healthiness is perceived to be low, we have positive birth selection while if parents are more likely to have a child when its inherent healthiness is perceived as low, we have negative birth selection. This means we could be over or under estimating the effect of spacing on child survival.

We address the issue of fertility selection on child health by estimating a two equation correlated hazard model for child mortality and the duration to next birth (following the birth of a particular child). ${ }^{4}$ Our approach, which relies on the methodology developed by Lillard (1993) and Brien and Lillard (1994), allows us to account for motherspecific unobserved heterogeneity that could reflect the unobserved differences in health or genetic endowment of mothers. This is modelled as a common mother-specific fixed effect. We allow these fixed effects to be correlated across the two hazard equations and have different impacts on birth spacing and child mortality. This correlation arises from the fact that the same individual makes both decisions: the duration between successive births and for given spacing, how much resource to allocate to each child (which is an important determinant of child quality). For example, the mother might have some private information regarding her health (unobserved to the researcher), which makes children born to this woman susceptible to some health condition that increases the chances of the child not surviving. But that might also make the mother choose a higher level of lifetime fertility (i.e., choose to reduce the duration between successive children).

While building on it, our paper is significantly different from Pitt (1997) in terns of the estimation methodology. Unlike Pitt (1997) who used random-effects bivariate probit models (with and without selection), we use a correlated recursive hazard model of spacing and survival. ${ }^{5}$ In an attempt to examine the robustness of our correlated estimates, we do

\footnotetext{
${ }^{4}$ Prior spacing is known by the time the context child is born and can therefore be treated as being exogenous.

${ }^{5}$ Our measure of child health pertains to the hazard of survival during the first 60 months of a child's life while fertility is related to the spacing between the context child and the immediately next child.
} 
however compare these correlated mortality hazard estimates with alternative estimates of mortality available in the literature, including the random effects bivariate probit estimates used by Pitt (1997). We also explore the role of breastfeeding as a possible behavioural mechanism to affect both fertility and child survival in our samples.

Our analysis is based on the National Family Health Survey (NFHS) 1992-93 data ${ }^{6}$ from the Indian province of Punjab and the Demographic and Health Survey (DHS) 1991 92 data from the Pakistani province of Punjab. A comparison of household behaviour in the Indian and Pakistani Punjab generates obvious interest: while households in these provinces share a common history, the institutional environments (particularly those pertaining to religious and political institutions) have evolved very differently over the last 60 years or so, following the partition of India in 1947. Given the common history of the two provinces, choice of our samples could potentially allow us to identify and evaluate the effects of institutions (e.g., religious and/or political) on differential fertility behaviour among sample households. There is confirmation of the fertility selection effects on mortality hazard rates and also the beneficial role of breastfeeding on both fertility and child health in our samples. These results also highlight the differential nature of demographic transition in these neighbouring provinces ruled by very different types of institutions since their partition in 1947.

\section{The Correlated Recursive Hazard Model}

The primary variable of our interest is the hazard of child mortality (i.e., child dying before reaching the age of 5 years), indicating the health status of a child born to a woman. An

\footnotetext{
${ }^{6}$ The second NFHS undertaken in 1998-99 was designed to strengthen the database further and facilitate implementation and monitoring of population and health programs in the country. Some additional information (e.g., height and weight of all eligible women, blood test for women and children) were collected. We decided to use the NFHS 1992-93 data because the survey years for India and Pakistan are then comparable. Preliminary analysis using the NFHS 1998-99 data yielded results similar to those reported here.
} 
individual woman, who has ever given birth, might be observed over the duration of one or more child births. From the time a child is born, the woman is at risk of having another child and also the child dying. Birth history of previous children is known and is exogenous in our analysis. We control for fertility selection by taking into account the potential endogeneity of duration to next birth on child mortality.

To be more specific, the log hazard of duration following the birth of the $i^{\text {th }}$ child $(i=1, \ldots, k)$ born to the $j^{\text {th }}$ woman $(j=1, \ldots, n)$ can be written as:

$$
h_{i j}^{n}=\beta_{0}+\beta_{1} T_{1}(t)+\beta_{2} X_{1 j}+\lambda_{j}^{n}+\varepsilon_{i j}^{n}
$$

and the log hazard of survival equation of the $i^{\text {th }}$ child born to the $j^{\text {th }}$ woman can be written as

$$
h_{i j}^{s}=\alpha_{0}+\alpha_{1} T_{2}(t)+\alpha_{2} X_{2 i j}+\lambda_{j}^{s}+\varepsilon_{i j}^{s}
$$

Here $X_{1 i j}$ and $X_{2 i j}$ denote two sets of exogenous and potentially endogenous explanatory variables that affect the hazards of duration to next birth and child mortality respectively. In our actual estimation we use a recursive system: time to next birth is included as an explanatory variable in the survival hazard regression but the number of months the child was alive, if he/she is dead at the time of the survey is not included as an explanatory variable in the hazard of duration to next birth regression. ${ }^{7}$ The explanatory variables $X_{1 i j}$ and $X_{2 i j}$ included in equations (1) and (2) consist of a set of child specific (variables particular to each birth), parental or household specific variables (common to all children in the household born to the same woman) and a set of period-specific dummies ${ }^{8}$ that may affect child survival and the duration to next birth.

\footnotetext{
${ }^{7}$ See section 4.3 that modifies this assumption to examine the importance of child replacement effect.

${ }^{8}$ In case of India, these variables relate to the decade the child was born, thus characterizing the nature of demographic transition over time (attributable, e.g., to socio-economic changes or improvements in the medical services). In the case of Pakistan, we include a dummy for the Islamaization of the country in 1977. See further discussion in section 3.
} 
The unexplained component of both the log hazard of survival and the log hazard of duration is broken up into a part that is purely random ( $\varepsilon_{i j}^{n}$ and $\varepsilon_{i j}^{s}$ in the two equations) and the components that is common to all children born to the same woman $\left(\lambda_{j}^{n}\right.$ and $\lambda_{j}^{s}$ in the two equations), that accounts for the unobserved mother/couple/household specific genetic, biological or health endowments common to all children born to the same woman. These unobserved heterogeneity terms are assumed to be uncorrelated with the other explanatory variables and also with the random error components $\left(\varepsilon_{i j}^{n}\right.$ and $\left.\varepsilon_{i j}^{s}\right)$ in the two regressions. We however allow the two unobserved heterogeneity components $\left(\lambda_{j}^{n}\right.$ and $\left.\lambda_{j}^{s}\right)$ to be correlated and assume joint normality of these residual terms in the two log hazard regressions i.e.,

$$
\left(\begin{array}{l}
\lambda_{j}^{n} \\
\lambda_{j}^{s}
\end{array}\right) \sim N\left(\left(\begin{array}{l}
0 \\
0
\end{array}\right),\left(\begin{array}{cc}
\sigma_{n}^{2} & \rho_{n s} \sigma_{n} \sigma_{s} \\
\rho_{n s} \sigma_{n} \sigma_{s} & \sigma_{s}^{2}
\end{array}\right)\right)
$$

Finally $\varepsilon_{i j}^{n} \sim \operatorname{IIDN}(0,1)$ and $\varepsilon_{i j}^{s} \sim \operatorname{IIDN}(0,1){ }^{9}$

$T_{1}(t)$ and $T_{2}(t)$ represent separate "clocks" of duration dependence of the hazards that determine the baseline hazard. They are essentially splines in time since the individual becomes at risk of the event. We denote the time at which an individual enters the risk of an event by $t_{0}$ and sub-divide the duration $t-t_{0}$ into $N_{i}+1$ discrete periods, which sum to the calendar time, but which allow the slope coefficients to differ within ranges of time separated by the $N_{i}$ nodes. Then the baseline log hazard function is defined as a spline or a piecewise linear function and the log hazard of the event will have different slopes over the

\footnotetext{
${ }^{9}$ In other words, we do not allow for any correlation between the unobserved child-specific heterogeneity in this correlated model. There may however remain some inputs in the health production function that depend on child-specific endowments. For example, the mortality or potential mortality of a particular child may be observed by the family prior to the conception of the next child but the variables affecting this decision are not directly observable in our data during the relevant prenatal period. Thus our estimates cannot take account of the potential bias generated by the possible correlation between the child-specific unobserved endowments in mortality and spacing decisions.
} 
duration. The baseline hazard functions can be written as:

$$
\begin{aligned}
& \beta_{1} T_{1}(t)=\sum_{k=1}^{N_{1}+1} \beta_{1 k} T_{1 k}(t) \\
& \alpha_{1} T_{2}(t)=\sum_{k=1}^{N_{2}+1} \alpha_{1 k} T_{2 k}(t)
\end{aligned}
$$

We estimate equations (1) and (2) jointly as a system of equations with the mother-specific errors correlated across the two equations. Denote $L^{n}\left(\lambda^{n}\right)$ and $L^{s}\left(\lambda^{s}\right)$ to be the conditional likelihood functions of the time to next birth and child survival respectively and we can write the joint marginal likelihood as:

$$
\iint_{\lambda^{n}} \prod_{\lambda^{s}} L^{n}\left(\lambda^{n}\right) \prod L^{s}\left(\lambda^{s}\right) f\left(\lambda^{n}, \lambda^{s}\right) d \lambda^{n} d \lambda^{s}
$$

Here $f\left(\lambda^{n}, \lambda^{s}\right)$ is the joint distribution of the unobserved heterogeneity components specified in equation (3). Thus conditional on the $\lambda$ residuals, birth spacing and child health are independent of one another and the conditional joint likelihood can be obtained by simply multiplying the individual likelihoods. The marginal joint likelihood is obtained by integrating out the heterogeneity terms (see Panis and Lillard (1994)). ${ }^{10}$ The complete model is estimated using Full Information Maximum Likelihood (FIML) method.

Child survival is defined as the age, in months, of the child at the time of the survey (if he/she is alive at the time of the survey) or number of months the child was alive (if he/she is dead at the time of the survey). The child who is alive at the time of the survey is regarded as being "censored". We restrict ourselves to child mortality in the age group $0-5$ years and children who are not alive at the time of the survey but were more than 5 years old at the time of death are also regarded as being censored. Birth spacing (or birth interval) is

\footnotetext{
${ }^{10}$ These models require that one or more residuals be integrated out. Where a closed form solution to the integral does not exist, the likelihood may be computed by approximating the normal integral by a weighted sum over conditional likelihoods, i.e., likelihoods are conditional on certain well-chosen values of the residual. The software that we use (Lillard and Panis (2003)) makes use of the Gauss-Hermite Quadrature to approximate normal integrals (e.g., Abramowitz and Stegun (1972), pp. 890 and 924).
} 
defined as the interval (defined in months) between the reported dates of birth. In case of the last child, the observed duration is the age of the child at the time of the survey and the observation is censored.

We use reported birth interval and not inter-conception interval. This implies that there could be some measurement error associated with this particular variable. So we cannot account for miscarriages, stillbirths and also pre-mature births. On the one hand, as Gribble (1993) argues, ignoring pre-mature births might make the observed birth intervals shorter. To examine this issue we re-estimated the equations after dropping all mothers with at least one birth interval less than 9 months. The results remain qualitatively similar. On the other hand ignoring miscarriages and stillbirths might make the observed interval longer. Furthermore, ignoring miscarriages and stillbirths might lead to an underestimation of the mortality effects of reduced birth intervals since miscarriages and stillbirths could be viewed as indications of unobserved health problems affecting the woman and that could also result in weaker live births (and increased child mortality). Unfortunately we do not have any systematic information on the incidence of miscarriages and stillbirths for each conception; all we can observe in our sample is if the woman ever had any miscarriage/stillbirth. ${ }^{11}$ Even this question was not administered in the Pakistan survey. For the Indian sample, where we do have information on ever experiencing miscarriages or stillbirths we computed the average months of survival and the average duration to next birth for sample women who have ever had a miscarriage or a stillbirth and for women who have not. The difference is not statistically significant in either case. ${ }^{12}$ In other words, we do not expect any bias in our central results, even if we include the possibility of miscarriage/still birth/abortion.

\footnotetext{
${ }^{11}$ To be specific the relevant question (v228) was whether the respondent ever had a pregnancy that terminated in a miscarriage, abortion, or still birth, i.e., did not result in a live birth.

${ }^{12}$ Mean Survival in months (if the child dies before reaching 5 years) is 11.7 months if the mother ever had a stillborn child or a miscarriage and 12.6 months if not ( $t$-value for test of difference $=-0.139$ ) and the mean posterior spacing (again if the child dies before reaching 5 years) is 31.3 months if the mother ever had a still born child or a miscarriage and 31.3 months if not ( $\mathrm{t}$-value for test of difference $=1.583$ ).
} 
We also examine the robustness of these results by computing: (1) single equation estimates for the log hazard of child survival, with and without unobserved mother level heterogeneity; (2) conditional fixed-effects logit estimates of child mortality (as a binary variable) with shorter duration (another binary variable) between successive births as one of the explanatory variables. The binary mortality variable takes a value 1 if a child dies within first 60 months of his/her life and is zero otherwise; birth spacing is defined to be "short" if the duration between two successive births is 15 months or less ${ }^{13}$ (3) random effects correlated bivariate probit estimates of child mortality and low birth spacing (both as binary variables). ${ }^{14}$

\section{Data, Descriptive Statistics and Explanatory Variables}

The empirical analysis is based on two data-sets collected around the same time: the NFHS 1992 - 93 data from India and the DHS 1990 - 91 data from Pakistan. We restrict ourselves to households residing in the Punjab province in the two countries. While the two countries differ significantly in terms of their religious and political institutions, households in these two provinces share a common socio-economic and linguistic background. GDP per capita is higher in Pakistan, but the households in India perform better in terms of demographic measures of well-being: the infant mortality rate, the crude birth rate and the total fertility rate are all lower and the adult literacy rates higher in India. ${ }^{15}$ Among the Indian states, as of

\footnotetext{
1315 months seems reasonable as we take account of exclusive breastfeeding for six months (as recommended by the UNICEF) or the time the mother may take, for example, to recover iron stores. In addition, we examined the robustness of using 15 months as the relevant definition for "short" spacing by re-estimating the regressions using 12 months as the relevant definition. The results remain qualitatively unchanged.

${ }^{14}$ Note that the probit specification does not use all available information (in particular it does not use the information on the number of months the child is alive if he/she is dead at the time of the survey). Also it is difficult to account for censoring as in the absence of longitudinal data we do not know the final health outcome of the child. For specifications (2) and (3) we restrict the sample to the non first-born and non-last born children.

${ }^{15}$ In 1992, the infant mortality rate was 79 per 1000 in India compared to 95 per 1000 in Pakistan, the crude birth rate was 29 per 1000 in India compared to 40 per 1000 in Pakistan and total fertility was 3.7 compared to 5.6 in Pakistan. Adult female literacy rates were $39 \%$ in India and $22 \%$ in Pakistan, while adult male literacy rates were $64 \%$ in India compared to $49 \%$ in Pakistan.
} 
1991 - 92, Punjab had the highest per capita net state domestic product and had the lowest

poverty rate. It is however worth noting that in terms of other demographic indicators

Punjab did not compare well with some of the other states in India. ${ }^{16}$ Among the four

Pakistani provinces, Punjab is the most prosperous and the most densely populated: more

than 56\% of all Pakistanis resided in Punjab in 1990. In terms of the other demographic and socio-economic indicators as well, Punjab performed better compared to the rest of Pakistan. ${ }^{17}$ While all households in the Pakistani sample are Muslims, most households in the Indian sample are either Sikhs (58\%) or Hindus (39\%), only $1.5 \%$ being Muslims. ${ }^{18}$

The Indian sample consists of 2995 women who have given birth to 8798 children.

Almost $40 \%$ of Indian women in the sample were sterilised at the time of the survey and we exclude the youngest child of these sterilized women from the estimating sample. ${ }^{19}$ This reduces the sample of children to 7896 of whom $51 \%$ were boys. About $34 \%$ of these children were first-born (this also includes the only children). 680 (approximately 8.6\%) of the children died before reaching age 10 and an overwhelming majority (71\%) of these children died before they were one year old. Average age at death (for the children that were

\footnotetext{
${ }^{16}$ For example in 1991 - 92, the net state output per capita in Punjab was double that of Kerala, however the infant mortality rate in Punjab (57 per 1000) was more than three times higher compared to that in Kerala (17 per 1000) and total fertility rate was close to double that of Kerala (3.1 compared to 1.8).

${ }_{17}$ The average number of years of education for women residing in Punjab was 1.34 years compared to 0.91 years for women residing in the rest of Pakistan; the corresponding numbers for men were 4.16 years compared to 3.33 for men residing in the rest of Pakistan. Average household income was significantly higher for households in Punjab compared to the rest of Pakistan.

18 This issue is important because it is now fairly well documented that Hindus and Muslims differ significantly in terms of their attitudes to son preference in different parts of South Asia. For example, Muthrayappa, Choe, Arnold and Roy (1997) find that compared to Hindus son preference is generally lower among Muslims in India except Jammu and Rajasthan. Arnold, Choe and Roy (1998) however argue that son preference has a negative effect on contraceptive use in Muslim dominated Bangladesh, regardless of socioeconomic and demographic characteristics. Hussain, Firkee and Berendes (2000) find gender of surviving children is strongly associated with subsequent fertility and contraceptive behaviour. Thus son preference in fertility/spacing even among Muslims in many parts of South Asia can generate an indirect but significant 'son preference' effect in child mortality, as the probability of child survival is closely linked to fertility/spacing through resource competition effect. Perhaps these factors, at least in part, could explain why number of children ever born and mortality rates are both significantly higher among Muslim households in the Indian Punjab.

${ }^{19}$ The decision to be sterilized is not exogenous so by excluding the youngest child of sterilized women from the estimating sample we are possibly creating a sample selection bias. We acknowledge this issue, but are unable to account for this in our estimation because of lack of adequate instruments and also the estimation methodology in that case becomes much more complicated.
} 
dead at the time of the survey) was 11.52 months and the mean duration between births was 30.26 months. We find statistically significant gender difference in child mortality $(z=2.887 ; p=0.004)$ but do not find a statistically significant effect of gender of the average duration to the next birth. $(z=0.562 ; p=0.574)$.

The Pakistani sample consists of 8814 children born to 1955 women. In this case too we exclude the youngest children born to women who were sterilized at the time of the survey. $51.08 \%$ of the final estimating sample was boys. $1179(13.38 \%)$ of the children died before reaching age 10 and again an overwhelming majority of these children $(72.43 \%)$ died before their first birthday. The average age at death of the children who were dead at the time of the survey was around 14 months and the average duration between births was 28 months. While there is no gender difference in child mortality $(z=0.363 ; p=0.7169)$, the average duration following the birth of a son is higher $(z=1.833 ; p=0.0668)$.

Table 1 presents the descriptive statistics for selected demographic variables in the two samples, which in turn reflect the differential demographic trend in the two provinces with different types of religious and political institutions.

The baseline hazards are specified as splines. We tried several specifications of the baseline hazard and chose the specification that fitted the data best (in terms of convergence of the baseline hazard function): for the Pakistani sample these turn out to be 12, 18, 24 and 30 months to characterize the baseline hazard in the log hazard of duration to next birth equation; the corresponding nodes for the Indian sample were at 12 and 24 months. The nodes to characterize the baseline hazard in the log hazard of child survival regression were 1 month for the Pakistani sample and 3 nodes at 3, 6 and 9 months for the Indian sample. The differences in the nodes between the two samples reflect the different distribution of birth spacing and child survival in the two samples. 
Identification is a difficult problem in this kind of modelling. Pitt and Rosenzweig (1989) rely on the non-linearity of the bivariate normal error distribution to identify the fertility selection-corrected reduced form models of birth weight. Lee, Rosenzweig and Pitt (1997) circumvent the problem by using instrumental variables to identify the health inputs in a health production function. Pitt (1997) took a different approach. He jointly estimated fertility, mortality and selected anthropometric indictors of child health. Our approach is similar to the last paper in that we make use of joint estimation of fertility and mortality to correct for selection bias though unlike in that paper and given the continuous nature of our mortality and fertility variables, we rely on a correlated recursive system of two hazard equations. Identification is ensured by the recursive nature of the system of equations. We include the time to next birth as an explanatory variable in the log hazard of survival regression but not the other way around. Effect of spacing in the mortality equation would not only highlight the role of maternal depletion on child survival (if spacing is short, for example), but also the economic effects of competition among consecutive siblings (especially if the spacing is short) for limited parental resources.

There however exist additional identifying variables that arise by the very nature of the particular decision - variables present in only one of the equations. This means that identification is not based solely on the recursive structure of the system of equations or non-linear nature of the likelihood function. Indicators for the type of toilet and the main source of drinking water are included as explanatory variables in the log hazard of child survival regression only: these capture the environment in which the child is born and grows up and could have a significant effect only on the health of the child, but have no direct relevance for the spacing equation. State dependence in child mortality is captured by including a binary indicator variable ANYPREVD, which takes the value of one if any of the previous children born to the woman has died. 
We expect composition of existing children to have an effect on the duration to the next birth only: to this end, we include in the log hazard of duration to next birth an indicator variable ALLPREVFEM, which takes the value of one if all of the previous children born to the woman are girls. Finally we include an indicator of contraception use EVERUSE in the log hazard of duration to next birth regression; the variable takes the value of one if the woman has ever used contraception. This variable captures the woman's attitude towards family planning and "choosing" the duration between children. ${ }^{20}$ These variables are unlikely to have any direct effect on child mortality.

\section{Empirical Analysis}

We start by examining the correlated hazard estimates of mortality for women with at least two children, thereby excluding the cases for only children (see Table 2 and Table 3 for the Indian and Pakistani sample respectively). We also exclude from our analysis the firstborn $^{21}$ and therefore restrict the sample to non-first-born children. We also exclude the youngest children of the sterilised couple since their posterior spacing is determined by parental action, i.e., sterilisation. We present the results on child mortality because that is the variable of primary interest in our analysis. The coefficient estimates for the birth spacing hazard regression are available on request.

\subsection{Correlated hazard estimates}

We present results corresponding to a number of different specifications. Specification 1 presents the single equation (uncorrelated) estimates of the log hazard of child survival ignoring mother level unobserved heterogeneity. Specification 2 presents the corresponding

\footnotetext{
${ }^{20}$ We could not use the information on contraception use at different points in the woman's life because that data is unavailable.

${ }^{21}$ For the first-born children, by definition sibling composition and mortality status of elder siblings is not defined, nor is the prior birth spacing. We computed the single-equation hazard estimates for the first-born children and these turned out to be very similar (for the common explanatory variables) to the non first-born children.
} 
estimates when we explicitly account for mother level unobserved heterogeneity. Specification 3 presents the correlated hazard estimates of the log hazard of child survival (from the joint estimation of equations (1) and (2)). Table 2 and Table 3 present the full set of estimates corresponding to the three specifications for the Indian and Pakistani samples respectively. In Table 4 we present the estimates for the unobserved heterogeneity components $\left(\sigma_{n}^{2}, \sigma_{s}^{2}, \rho_{n s}\right)$. These estimates show that ignoring mother level unobserved heterogeneity results in biased estimates and also that the single equation estimates are inconsistent: the correlation between the unobserved heterogeneity coefficients $\left(\rho_{n s}\right)$ is statistically significant in both regressions.

A negative (positive) and statistically significant coefficient associated with any particular variable in the log hazard of child mortality regression implies that this variable reduces (increases) the hazard of child mortality and increases (decreases) the number of months the child was alive if he/she is dead at the time of the survey.

We start with the results for the sample of Indian households (Table 2). There is evidence of a statistically significant effect of birth spacing on child survival: an increase in the duration between child $i$ and child $i+1$ significantly reduces the log hazard of child mortality (equivalently increases the survival chances of the child). In addition to posterior spacing, longer prior birth spacing also has a statistically significant effect on the hazard of child survival: an increase in the duration between child $i-1$ and child $i$ also significantly reduces the hazard of child mortality. These results are compatible with both economic and biological explanations of mortality. First, shorter spacing is indicative of significant competition among siblings for limited parental resources, especially in low-income regions; clearly this competition will be intense if spacing is shorter. Second, shorter birth spacing is also indicative of maternal depletion effect (attributable to both breastfeeding as well as deficiency of essential micro nutrients among women in resource constrained 
households, especially in low-income countries), which in turn may result in an adverse effect on child health.

We do not find any direct evidence of gender difference in the hazard of child mortality: the child gender dummy is not statistically significant. The hazard of mortality of the index child is significantly lower if all of the previous children born to the woman are girls. Mortality of older siblings is however associated with a significant increase in the log hazard of mortality of the index child. Mortality of older siblings could be indicative of some kind of health or genetic problem of the mother so that mortality tends to be experienced by certain families . Additionally, parents may not learn from the death of one child and a subsequent child may die of a similar cause (for, example, diarrhoea, which is a common cause of child mortality in developing countries). Finally, there can be some intrahousehold heterogeneity arising from a close correlation between this child specific variable and the unobserved child-specific error term that we assume away in our estimates. ${ }^{22}$

Parental characteristics seem to have a fairly limited effect on the hazard of child mortality. The hazard of child mortality is significantly lower for wealthier households. Access to modern toilet facilities significantly (though only at the $10 \%$ level) reduces the hazard of child mortality and this reflects the role of provision of services (role of supply side factors) in reducing child mortality and improving child health. Finally relative to children born before 1970, the log hazard of child mortality is significantly lower for children born during the period 1980 - 1990. The latter may be indicative of better provision of child immunisation and other health care services in the $80 \mathrm{~s}$.

Table 3 presents the coefficient estimates for the sample of Pakistani households. As with the Indian case, there is evidence of maternal depletion/sibling competition effect in the Pakistani sample: an increase in the duration between child $i$ and child $i+1$

\footnotetext{
${ }^{22}$ We re-estimated the regressions ignoring this particular variable and the results are qualitatively similar. These results are available on request.
} 
significantly reduces the hazard of child mortality. Additionally an increase in the duration between child $i-1$ and child $i$ is also associated with a significant reduction in the hazard of mortality of child $i$. Mortality of elder siblings is associated with an increase in the hazard of child mortality ${ }^{23}$ though the gender of either the index child or of elder siblings does not have a statistically significant effect on the hazard of child mortality.

The hazard of child mortality is significantly lower (equivalently the health of the child is significantly better) for children with educated mothers and additionally the hazard of child mortality is significantly lower for children born to older mothers. The higher the educational attainment of the mother the stronger is the impact of mother's educational attainment on child health (the lower is the hazard of child mortality) and the higher is the age of the mother at the time of birth, the stronger is the effect of mother's age on child health. The fact that the mother's educational attainment has a strong effect on child health is not surprising. It is argued that women's education increase labour market participation and provides better employment opportunities and hence raises their incomes. This raises the status of women both in society and within the family, especially in poor Asian societies. There are significant positive externalities to such a process - an increase in the age at marriage and reduction in fertility rates and an increased investment in child quality. Evaluation of the benefits from educating women have led economists and policy makers to argue that educating women yields substantial benefits in the form of higher economic returns compared to similar expenditures on men (see Schultz (2002)).

The hazard of child mortality is significantly higher for children born in rural households - this possibly reflects poorer health services and facilities in rural areas compared to urban areas. Finally the hazard of child mortality is significantly higher for children born after 1977. It appears that an absence of a tight family planning and maternal

\footnotetext{
${ }^{23}$ The results are robust to re-estimation ignoring this particular variable.
} 
health programs, especially after the Islamization of the country in 1977, had a strong adverse effect on child health in Pakistan. ${ }^{24}$

\subsection{A comparison with alternative estimates}

In this section, we compare the correlated survival hazard estimates with the alternative mortality estimates available in the literature. We focus on three possible alternatives: (i) Conditional fixed effects single-equation logit estimates of mortality that takes account of the unobserved family-specific fixed effects, but are uncorrected for the potential choicebased nature of birth spacing. (ii) Random effects single-equation probit estimates of mortality. (iii) Random-effects bivariate probit estimates with non-zero correlation where both fertility and posterior spacing are binary in nature. In particular, the binary mortality variable is 1 if the child dies within first 5 years of its life while the spacing/fertility variable takes a value 1 if the posterior spacing between the context child and the immediately next one is less than or equal to 15 months. These binary probit specifications of fertility and mortality do not use the information on the number of months a child is alive if he/she is dead at the time of the survey or the exact birth interval between the context child and the immediately next child; in other words, probit estimates treat all mortality/fertility on the same scale; the hazard estimates however make use of the actual duration of survival and birth interval.

These alternative estimates are summarised in Table 5 and Table 6 respectively for the Indian and the Pakistani samples. The effect of spacing is significant in all different

\footnotetext{
${ }^{24}$ The effect of resource constraints on the index child might however be different depending not only on the gender of the current child but also on the gender composition of the previous children born to the couple. To examine this issue we re-estimated the regression but this time we included an additional explanatory variable: the interaction of the gender of the index child (BOY) and a dummy for all previous children born to the couple being girls (ALLPREVFEM). In this case the non-interacted coefficient ALLPREVFEM gives us the effect of gender composition of elder siblings on girls while the interaction term gives us the differential effect. The results for the Pakistani sample (but not for the Indian sample) show that the male child is significantly better off (in terms of resources devoted to him leading to better health outcomes) if all the elder siblings are girls. The results are available on request. There is thus confirmation that sibling gender composition has an important influence on intra-household resource allocation of resources, particularly if the child comes from a poor, resource-constrained household and the results hold even after allowing for fertility selection, thus corroborating the single-equation mortality estimates of Garg and Morduch (1998) and Morduch (2000).
} 
specifications (the probability of child mortality is significantly higher if posterior spacing is short $(<15$ months $)$ ), though the size of the coefficient varies considerably across the specifications. Note however that the correlation coefficient in the bivariate probit model is not statistically significant for the Pakistan sample, thus raising doubts about the relevance of this model for the Pakistani sample. ${ }^{25}$

While the bivariate probit estimates of mortality appear to be qualitatively similar to the correlated hazard estimates of mortality in our samples, the latter seem to fit our samples better; note that the bivariate probit correlation coefficient fails to be significant in the Pakistani case. Additionally the maximised value of log-likelihood is much higher for the correlated hazard estimates for both samples and the likelihood ratio statistics are also highly significant in each case (see Table 7). The present paper thus identifies an important alternative to the bivariate probit model that estimates mortality after correcting for the selfselection in fertility decisions.

\subsection{Is there any reverse effect of child survival on child spacing?}

There is however another side to this story that we have not yet addressed. Just as shorter birth interval may induce more maternal depletion, thus affecting child survival, early child death may also result in a reduction in the duration between successive children because parents want to replace children that have died. This is known as the child replacement effect (see for example Zenger (1993). In this case the hazard of subsequent birth depends on child survival, controlling for other individual, sibling, parental, household and community characteristics.

\footnotetext{
${ }^{25}$ We have also estimated random effects bivariate probit model with selection for spacing (which as we have noted earlier is defined to be longer than 15 months). This is closest to the selection-corrected random effects bivariate probit estimates in Pitt (1997). The resultant selectivity-corrected bivariate probit mortality estimates however pertain to children with longer posterior spacing (which cannot include spacing as one of the explanatory variables) and is therefore of little direct relevance for our purpose.
} 
To examine this child replacement hypothesis, we estimated a reverse correlated hazard system. While the estimating equations are similar to those in (1) and (2), there is one crucial difference: in order to maintain the recursive structure of the system of equations, we include the number of months the child was alive, if he/she is dead at the time of the survey as an additional explanatory variable in the hazard of duration to next birth regressionn but the time to next birth is not included as an explanatory variable in the survival hazard regression in this case.

The results for this specification are presented in Table 8 (column 1 for the Indian sample and column 2 Pakistani sample). We present results for the complete specification (corresponding to specification 3 in Table 2 and Table 3$).{ }^{26}$ Our results show that the child replacement effect is significant in the Indian sample, but not in the Pakistani sample. In other words, increased child survival could increase birth spacing in India though not in Pakistan. This difference could be taken to be a reflection of a generally passive (and sometimes actively negative) role of institutions in Pakistan to induce fertility planning, thus resulting in different fertility behaviour of households in these two neighbouring states.

\subsection{Effect of Breastfeeding}

While our analysis has made a strong case for an inverse relationship between birth spacing and child mortality, we have not yet discussed any possible biological/behavioural mechanism that may induce this relationship. As the anonymous referees have pointed out, breastfeeding might play an important role in this respect: not only is the duration of breastfeeding closely correlated with birth interval (Jain and Bongaarts (1981)), but also it improves the likelihood of survival among infants. First the primary link between breastfeeding and birth spacing arises because breastfeeding increases the post partum amenorrhoea, i.e., the time between a birth and resumption of the menstruation (Jain, Hsu,

\footnotetext{
${ }^{26}$ The full set of results are available on request.
} 
Freedmand and Chang. (1970)). Secondly, breast milk is extremely nutritious for the infant and also contains immunological elements that provide protection against different forms of infections among infants; thus breastfeeding improves the survival chances of infants. Given this close biological link between breastfeeding on the one hand and birth spacing and survival on the other, we shall now examine the effects of breastfeeding on birth spacing and child mortality in our samples.

The majority of women in our sample breastfeed their children, though the duration of breastfeeding varies considerably. The major obstacle to include the duration of breastfeeding as an additional explanatory variable in the regressions arises from the fact that the data on this particular variable was not collected for the full sample. ${ }^{27}$ Information on duration of breastfeeding was only collected for children born during the period 1986 1991 (the five years preceding the survey) in Pakistan and during the period $1989-1992$ (the three years preceding the survey) in India. So the sample size is now considerably smaller. In particular we now have information on 2153 children born to 1328 mothers in Pakistan and 1613 children born to 1135 mothers in India. For the Pakistan sample, the average duration of breastfeeding is nearly 14 months and for the Indian sample the corresponding duration is 13 months (for the sample of children that have ever been breastfed); $8.6 \%$ of the children in Pakistan and $4.53 \%$ of the children in India have never been breastfed.

To examine whether breastfeeding has any effect on the duration to next birth (NEXT) and child mortality (SURV) we present in Figure 1 and Figure 2 the effect of ever breastfeeding on NEXT and SURV respectively (for Pakistan and India). Figure 1 implies that the hazard of having a younger sibling is not significantly different depending on whether or not the child has been breastfed. Using a non-parametric Wilcoxon test we are

\footnotetext{
${ }^{27}$ For the Indian sample, we only observe if a child has ever been breastfed; this data is however not available for the Pakistani sample.
} 
not able to reject the null hypothesis of equality of the survivor functions $\left(\chi^{2}(1)=1.33 ; p-\right.$ value $=0.2493$ for Pakistan and $\chi^{2}(1)=0.00 ; p-$ value $=0.9916$ for India). On the other hand, Figure 2 implies that for both Pakistan and India, the hazard of child mortality is significantly higher for infants that are never breastfed and this difference is particularly significant for the first 6 months of the child's life. Using a non-parametric Wilcoxon test, we reject the null hypothesis of equality of the survivor functions $\left(\chi^{2}(1)=996.41 ; p-\right.$ value $=0.0000$ for Pakistan and $\chi^{2}(1)=307.11 ; p-$ value $=0.0000$ for India).

Finally and subject to these data constraints, we attempt to integrate the possibility of breastfeeding in our analysis of child mortality with fertility selection. The most obvious estimation methodology would be to estimate a three-equation correlated hazard system (breastfeeding, posterior spacing, and child mortality). This would address the self-selection issues attached to both fertility and breastfeeding. However when we do that, we cannot reject the null hypothesis of zero pair-wise correlation between the unobserved components of the error terms in these three equations for the Pakistani sample and the system does not attain convergence in the Indian sample. ${ }^{28}$ We then move to the next best solution: we reestimate the two equation correlated hazard system (posterior spacing is included as an explanatory variable in the child mortality regression) with breastfeeding as an additional exogenous explanatory variable (in both regressions). Given that a large very proportion (more than 90\%) of women in our samples breastfeed their children (though the duration may vary), one could argue that breastfeeding is a cultural custom in this part of the world. This to some extent justifies our assumption of treating breastfeeding as an exogenous variable (as opposed to a choice variable) in the regressions. How breastfeeding is measured is unfortunately different in the two cases. In the Pakistani case we include the number of

\footnotetext{
${ }^{28}$ These results are available on request.
} 
months the child was breastfed (duration of breastfeeding). In the Indian case the relevant variable is whether the child was ever breastfed. This is because the system fails to converge if we used the duration of breastfeeding as the relevant variable in the Indian sample (available only for the children born in the last 5 years). This is possibly due to the fact for the Indian sample we have very few women giving births to more than one child in the relevant period.

Our results (see Table 9) highlight the direct and beneficial effects of breastfeeding on child mortality in both samples. The effect on birth spacing is however not as strong as one would have expected: for the Indian sample, breastfeeding does not have a statistically significant effect on the duration to next birth. For the Pakistani sample, however we use the sub-sample of children born during last 5 years of the survey and find that the duration of breastfeeding has a negative and statistically significant effect on duration to next birth as well as child mortality. Although we cannot generate comparable estimates for both the samples, there is some confirmation that both the possibility and duration of breastfeeding exert beneficial influence (direct and/or indirect) on child survival in our samples.

\subsection{A Comparative Perspective}

Results from the correlated hazard model from the two samples of our choice is quite interesting in itself and among other things highlight the differential nature of household behaviour in the two neighbouring provinces governed by different religious and political institutions since their partition in 1947. First, a comparison of the spacing effects in specifications (1) and (3) are interesting and they highlight the differential fertility selection effects of mortality in the two provinces. Note that compared to specification (1), corrected coefficients of prior and posterior spacing are smaller for India but larger for Pakistan. Given that there could be both positive and negative selection effects of fertility, this would reflect that negative effects dominate for India while the reverse is true for Pakistan. 
Second, compared to the households in the Indian province, there is evidence of a more pronounced effect of maternal literacy on spacing and mortality in the Pakistani province and this holds even after controlling for all other possible factors influencing the relationships. Third, child replacement effect is strong in the case of India but not in the case

of Pakistan. Fourth, the beneficial effect of breastfeeding on spacing is pronounced only in Pakistan. Finally, while the hazard of subsequent birth has been declining in India in recent decades, the trend has been just opposite in Pakistan, especially following the introduction of the Islamic state in 1977, even after controlling for household religion, literacy and assets. In other words, after controlling for all possible factors, differential role of maternal education, child survival as well as breastfeeding on household fertility behaviour in these two neighbouring provinces is likely to be a reflection of a rather passive (and sometimes actively negative) official population policy in Pakistan (vis-à-vis India) for much of the post-independence period.

\section{Conclusion}

Much of the existing literature on child health and child mortality in developing countries is derived from the estimation of reduced form estimates of child health functions, ignoring the effects of fertility selection. This paper in contrast argues that fertility selection plays an important role in the explanation of child mortality. Not accounting for this selection issue leads to a potential selection bias and it is difficult to a priori predict the direction of this bias, thereby over or under estimating the effect of spacing on child survival. In our analysis, both spacing and mortality are modelled as correlated hazard functions, which allow us to address the bias generated by the selective nature of spacing/fertility decisions by parents. We find that the estimates of birth spacing on child mortality are different when we do not account for fertility selection. One big advantage of the methodology that we 
adopt in this paper is that unlike bivariate probit model used in the literature, the correlated hazard model uses all the available information pertaining to fertility/spacing and mortality. We also explore the beneficial role of breastfeeding as a possible behavioural mechanism on both fertility and child survival.

High fertility is often associated with high child mortality, especially in low-income countries; though addressing the effects of fertility on child mortality is more complex than it first appears. This is because of the two-way causality between these two decisions. The present paper in this respect offers a method of dealing with the often neglected issue of fertility selection in the two neighbouring provinces sharing common socio-cultural background, but governed by very different institutions since their partition in 1947. This is crucial not only for an understanding of the demographic transition in this region, but also to identify the role of the state to shape the demographic transition necessary for economic growth. 


\section{REFERENCES}

Abramowitz, M. and I. A. Stegun (1972): Handbook of Mathematical Functions, New York, Dover Publications Inc.

Arnold, F., M. K. Choe and T. K. Roy (1998): "Son Preference, the Family-building Process and Child Mortality in India", Population Studies, 52, 301 - 315.

Brien, M. J. and L. A. Lillard (1994): "Education, Marriage, and First Conception in Malaysia", Journal of Human Resources, 29(4), 1166 - 1204.

Garg, A. and J. Morduch (1998): "Sibling Rivalry and the Gender Gap: Evidence from Child Health Outcomes in Ghana", Journal of Population Economics, 11(4), 471 - 493.

Gribble, J. N. (1993): "Birth intervals, gestational age and low birth weight: are the relationships confounded?" Population Studies, 47, 133 - 146.

Hussain, R. F., F. Firkee and H. W. Berendes (2000): "The Role of Son Preference in Reproductive Behaviour in Pakistan", Bulletin of World Health Organisation, 78(3), 379 388.

Jain, A. K. and J. Bongaarts (1981): "Breastfeeding: Patterns, Correlates and Fertility Effects", Studies in Family Planning, 12(3), 79 - 99.

Jain, A. K., T. C. Hsu, R. Freedmand and M. C. Chang. (1970): "Demographic Aspects of Lactation and Postpartum Amenorrhea", Demography, 7(2), 255 - 270.

Lee, L.-f., M. R. Rosenzweig and M. M. Pitt (1997): "The effects of improved nutrition, sanitation, and water quality on child health in high-mortality populations", Journal of Econometrics, 77(1), 209-235.

Lillard, L. A. (1993): "Simultaneous Equations for Hazards: Marriage Duration and Fertility Timing", Journal of Econometrics, 56(1-2), 189 - 217.

Lillard, L. A. and C. W. A. Panis (2003): Multiprocess Multilevel Modelling, Econware, Los Angeles, California.

Makepeace, G. and S. Pal (2007): "Understanding the Effects of Siblings on Child Mortality: Evidence from India", Journal of Population Economics, Forthcoming.

Morduch, J. (2000): "Sibling Rivalry in Africa", The American Economic Review, 90(2), 405-409.

Muthrayappa, R., M. K. Choe, F. Arnold and T. K. Roy (1997). Son Preference and Its Effect on Fertility in India. National Family Health Survey Subject Reports No. 3.

Panis, C. W. A. and L. A. Lillard (1994): "Health inputs and child mortality: Malaysia", Journal of Health Economics, 13(4), 455-489. 
Pitt, M. M. (1997): "Estimating the Determinants of Child Health When Fertility and Mortality Are Selective", Journal of Human Resources, 32(1), 129-158.

Pitt, M. M. and M. R. Rosenzweig (1989): "The Selectivity of Fertility and the Determinants of Human Capital Investments: Parametric and Semi-Parametric Estimates". LSMS Working Paper No. 72.

Schultz, T. P. (2002): "Why Governments Should Invest More to Educate Girls", World Development, 30(2), 207 - 225.

Zenger, E. (1993): "Siblings' Neonatal Mortaility Risks and Birth Spacing in Bangladesh", Demography, 30(3), 477 - 488. 


\section{TABLES}

Table 1: Means and standard deviations of Selected Demographic Variables

\begin{tabular}{lcc}
\hline Variable & India & Pakistan \\
\hline Oldest Child & 0.3102 & 0.2218 \\
& $(0.45)$ & $(0.42)$ \\
Youngest Child & 0.2709 & 0.2098 \\
& $(0.44)$ & $(0.41)$ \\
Dead at the Time of the Survey & 0.0826 & 0.1338 \\
& $(0.28)$ & $(0.34)$ \\
SURV (in months, sample not censored) & 11.52 & 13.95 \\
NEXT (in months, sample not censored) & $(17.88)$ & $(26.28)$ \\
& 30.26 & 27.90 \\
Children ever born & $(16.47)$ & $(16.06)$ \\
& 4.02 & 4.22 \\
Highest School Attainment of Mother: Primary School (EDUCM1) & $(1.65)$ & $(3.00)$ \\
Highest School Attainment of Mother: More than Primary School & 0.1639 & 0.1171 \\
(EDUCM2) & $(0.37)$ & $(0.32)$ \\
Highest School Attainment of Father: Primary School (EDUCF1) & 0.20 & 0.1908 \\
& $(0.40)$ & $(0.39)$ \\
Highest School Attainment of Father: More than Primary School & - & 0.1488 \\
(EDUCF2) & & $(0.36)$ \\
If father is literate (LITDAD) & - & 0.4353 \\
\end{tabular}

Note: Standard deviations in parentheses. 
Table 2: Uncorrelated and correlated mortality hazard estimates, India

\begin{tabular}{|c|c|c|c|}
\hline & \multicolumn{2}{|c|}{ Uncorrelated hazard estimates } & \multirow{2}{*}{$\begin{array}{l}\text { Correlated hazard estimates } \\
\text { (3) With heterogeneity }\end{array}$} \\
\hline & $\begin{array}{c}\text { (1) No } \\
\text { heterogeneity }\end{array}$ & (2) With heterogeneity & \\
\hline $0-3$ months & $\begin{array}{c}-1.1872 * * * \\
(0.1186)\end{array}$ & $\begin{array}{c}-1.1839 * * * \\
(0.1197)\end{array}$ & $\begin{array}{c}-1.1739 * * * \\
\quad(0.1206)\end{array}$ \\
\hline 3-6 months & $\begin{array}{c}0.2149 \\
(0.1511)\end{array}$ & $\begin{array}{c}0.2118 \\
(0.1515)\end{array}$ & $\begin{array}{c}0.194 \\
(0.1526)\end{array}$ \\
\hline 6-9 months & $\begin{array}{c}-0.1747 * \\
(0.1035)\end{array}$ & $\begin{array}{l}-0.1695 \\
(0.1035)\end{array}$ & $\begin{array}{l}-0.1498 \\
(0.1049)\end{array}$ \\
\hline$>9$ months & $\begin{array}{c}-0.0292 * * * \\
(0.0042)\end{array}$ & $\begin{array}{c}-0.0293 * * * \\
(0.0042)\end{array}$ & $\begin{array}{c}-0.0289 * * * \\
(0.0044)\end{array}$ \\
\hline Intercept & $\begin{array}{c}-0.474 \\
(1.0744)\end{array}$ & $\begin{array}{l}-0.4878 \\
(1.1598)\end{array}$ & $\begin{array}{l}-0.3772 \\
(1.051)\end{array}$ \\
\hline Boy & $\begin{array}{l}-0.0324 \\
(0.1051)\end{array}$ & $\begin{array}{l}-0.0275 \\
(0.1062)\end{array}$ & $\begin{array}{l}-0.0544 \\
(0.1071)\end{array}$ \\
\hline All sisters & $\begin{array}{c}-0.4558 * * * \\
(0.1357)\end{array}$ & $\begin{array}{c}-0.4549 * * * \\
(0.1373)\end{array}$ & $\begin{array}{c}-0.4637 * * * \\
(0.1383)\end{array}$ \\
\hline Previous child dead & $\begin{array}{c}0.8020 * * * \\
(0.1128)\end{array}$ & $\begin{array}{c}0.7297 * * * \\
(0.1394)\end{array}$ & $\begin{array}{c}0.7895 * * * \\
(0.1394)\end{array}$ \\
\hline Prior spacing & $\begin{array}{c}-0.0334 * * * \\
(0.0052)\end{array}$ & $\begin{array}{c}-0.0338 * * * \\
(0.0054)\end{array}$ & $\begin{array}{c}-0.0390 * * * \\
(0.0058)\end{array}$ \\
\hline Posterior spacing & $\begin{array}{c}-0.0163 * * * \\
(0.0032)\end{array}$ & $\begin{array}{c}-0.0165 * * * \\
(0.0032)\end{array}$ & $\begin{array}{c}-0.0209 * * * \\
(0.0067)\end{array}$ \\
\hline Mother's age 21-25 & -0.0464 & -0.0485 & 0.0041 \\
\hline yis & $(0.221)$ & $(0.225)$ & $(0.226)$ \\
\hline Mother's age & 0.1267 & 0.1197 & 0.1949 \\
\hline & $(0.231)$ & $(0.2366)$ & $(0.2385)$ \\
\hline Mother's age & 0.0079 & -0.0113 & 0.1074 \\
\hline & $(0.2932)$ & $(0.3007)$ & $(0.3022)$ \\
\hline Father is literate & $\begin{array}{c}0.1486 \\
(0.1277)\end{array}$ & $\begin{array}{c}0.1526 \\
(0.1345)\end{array}$ & $\begin{array}{c}0.1618 \\
(0.1326)\end{array}$ \\
\hline Mother has primary & 0.0533 & 0.0459 & 0.0675 \\
\hline & $(0.1762)$ & $(0.184)$ & $(0.184)$ \\
\hline Mother has & 0.3478 & 0.3574 & 0.3564 \\
\hline & $(0.2187)$ & $(0.2249)$ & $(0.2242)$ \\
\hline Hindu & $\begin{array}{c}0.0599 \\
(0.1202)\end{array}$ & $\begin{array}{c}0.0656 \\
(0.1261)\end{array}$ & $\begin{array}{c}0.096 \\
(0.1246)\end{array}$ \\
\hline Muslim & $\begin{array}{l}-0.3871 \\
(0.3439)\end{array}$ & $\begin{array}{l}-0.3725 \\
(0.3593)\end{array}$ & $\begin{array}{l}-0.3776 \\
(0.3689)\end{array}$ \\
\hline
\end{tabular}




\section{Table 2 Continued}

\begin{tabular}{|c|c|c|c|}
\hline & \multicolumn{2}{|c|}{ Uncorrelated hazard estimates } & \multirow{2}{*}{$\begin{array}{l}\text { Correlated hazard estimates } \\
\text { (3) With heterogeneity }\end{array}$} \\
\hline & $\begin{array}{c}\text { (1) No } \\
\text { heterogeneity }\end{array}$ & (2) With heterogeneity. & \\
\hline \multirow[t]{2}{*}{ Other religions } & 0.4261 & 0.4196 & 0.4248 \\
\hline & $(0.5063)$ & $(0.5354)$ & $(0.5337)$ \\
\hline \multirow{2}{*}{$\begin{array}{l}\text { Composite assets } \\
\text { index }\end{array}$} & $-0.4139 * * *$ & $-0.4181 * * *$ & $-0.4103 * * *$ \\
\hline & $(0.0748)$ & $(0.078)$ & $(0.0766)$ \\
\hline \multirow[t]{2}{*}{ Modern Toilet } & $-0.2791 *$ & -0.2737 & -0.2475 \\
\hline & $(0.1626)$ & $(0.1687)$ & $(0.1653)$ \\
\hline \multirow[t]{2}{*}{ Safe drinking water } & -0.946 & -0.9715 & -0.9231 \\
\hline & $(1.0367)$ & $(1.126)$ & $(1.0001)$ \\
\hline \multirow[t]{2}{*}{ RURAL } & 0.0918 & 0.1019 & 0.1405 \\
\hline & $(0.1624)$ & $(0.1696)$ & $(0.1679)$ \\
\hline \multirow[t]{2}{*}{ Born in the $1970 \mathrm{~S}$} & $-0.3861 *$ & $-0.3992 * *$ & $-0.3557 *$ \\
\hline & $(0.1983)$ & $(0.2024)$ & $(0.2085)$ \\
\hline \multirow[t]{2}{*}{ Born in the $1980 \mathrm{~S}$} & $-0.4652 * *$ & $-0.4714 * *$ & $-0.4504 * *$ \\
\hline & $(0.1985)$ & $(0.2054)$ & $(0.2076)$ \\
\hline \multirow[t]{2}{*}{ Born in the $1990 \mathrm{~S}$} & -0.4781 & -0.4798 & -0.4975 \\
\hline & $(0.3158)$ & $(0.3321)$ & $(0.334)$ \\
\hline Log-L & -2290.35 & -2289.80 & -14526.16 \\
\hline
\end{tabular}

NOTE: Asymptotic standard errors in parentheses; Significance: '*'=10\%; '**'=5\%; '***'=1\%. 
Table 3: Uncorrelated and Correlated Mortality Hazard Estimates, Pakistan

\begin{tabular}{|c|c|c|c|}
\hline & \multicolumn{2}{|c|}{ Uncorrelated hazard estimates } & \multirow{2}{*}{$\begin{array}{c}\text { Correlated hazard } \\
\text { estimates } \\
\text { (3) with } \\
\text { heterogeneity }\end{array}$} \\
\hline & (1) No heterogeneity & $\begin{array}{c}\text { (2) with } \\
\text { heterogeneity }\end{array}$ & \\
\hline Spline: $0-1$ month & $\begin{array}{c}-0.8119 * \\
(0.4808)\end{array}$ & $\begin{array}{l}-0.7198 \\
(0.4908)\end{array}$ & $\begin{array}{l}-0.6930 \\
(0.5014)\end{array}$ \\
\hline Spline: $>1$ month & $\begin{array}{c}-0.0629 * * * \\
(0.0014)\end{array}$ & $\begin{array}{c}-0.0621 * * * \\
(0.0014)\end{array}$ & $\begin{array}{c}-0.0619 * * * \\
(0.0014)\end{array}$ \\
\hline Constant & $\begin{array}{c}-2.8188 * * * \\
(0.4774)\end{array}$ & $\begin{array}{c}-2.9358 * * * \\
(0.4953)\end{array}$ & $\begin{array}{c}-3.0835 * * * \\
(0.5039)\end{array}$ \\
\hline Boy & $\begin{array}{l}-0.0423 \\
(0.0660)\end{array}$ & $\begin{array}{l}-0.0421 \\
(0.0679)\end{array}$ & $\begin{array}{l}-0.0466 \\
(0.0688)\end{array}$ \\
\hline Posterior spacing & $\begin{array}{c}-0.0083 * * * \\
(0.0013)\end{array}$ & $\begin{array}{l}-0.0089 * * * \\
(0.0013)\end{array}$ & $\begin{array}{c}-0.0065 * * * \\
(0.0014)\end{array}$ \\
\hline Prior spacing & $\begin{array}{c}-0.0277 * * * \\
(0.0025)\end{array}$ & $\begin{array}{l}-0.0288 * * * \\
(0.0025)\end{array}$ & $\begin{array}{l}-0.0253 * * * \\
(0.0027)\end{array}$ \\
\hline Any previous child dead & $\begin{array}{c}0.8716 * * * \\
(0.0648)\end{array}$ & $\begin{array}{c}0.7532 * * * \\
(0.0818)\end{array}$ & $\begin{array}{c}0.7130 * * * \\
(0.0834)\end{array}$ \\
\hline Mother's age: $21-25$ & $\begin{array}{c}-0.2353 * * * \\
(0.0838)\end{array}$ & $\begin{array}{l}-0.2244 * * \\
(0.0891)\end{array}$ & $\begin{array}{l}-0.2698 * * * \\
(0.0921)\end{array}$ \\
\hline Mother's age: $26-30$ & $\begin{array}{c}-0.4398 * * * \\
(0.1005)\end{array}$ & $\begin{array}{c}-0.4487 * * * \\
(0.1094)\end{array}$ & $\begin{array}{c}-0.5357 * * * \\
(0.1133)\end{array}$ \\
\hline Mother's age: $>30$ & $\begin{array}{c}-0.8721 * * * \\
(0.1741)\end{array}$ & $\begin{array}{c}-0.8993 * * * \\
(0.1977)\end{array}$ & $\begin{array}{c}-1.0631 * * * \\
(0.2078)\end{array}$ \\
\hline Father's age: $26-30$ & $\begin{array}{c}-0.4189 * * * \\
(0.1369)\end{array}$ & $\begin{array}{c}-0.4523 * * * \\
(0.1547)\end{array}$ & $\begin{array}{c}-0.4896 * * * \\
(0.1564)\end{array}$ \\
\hline Father's age: $31-35$ & $\begin{array}{l}-0.0424 \\
(0.0893)\end{array}$ & $\begin{array}{l}-0.0413 \\
(0.0969)\end{array}$ & $\begin{array}{l}-0.0155 \\
(0.0977)\end{array}$ \\
\hline Father's age: $>36$ & $\begin{array}{c}0.0319 \\
(0.0831)\end{array}$ & $\begin{array}{c}0.0313 \\
(0.0951)\end{array}$ & $\begin{array}{c}0.0291 \\
(0.0975)\end{array}$ \\
\hline $\begin{array}{l}\text { Highest education attained by } \\
\text { mother is primary school }\end{array}$ & $\begin{array}{c}-0.3096 * * \\
(0.1365)\end{array}$ & $\begin{array}{c}-0.3380 * * \\
(0.1622)\end{array}$ & $\begin{array}{l}-0.3335 * * \\
(0.1649)\end{array}$ \\
\hline Highest education attained by & $-0.4550 * * *$ & $-0.4876 * * *$ & $-0.5290 * * *$ \\
\hline mother is more than primary school. & $(0.1508)$ & $(0.1741)$ & $(0.1837)$ \\
\hline $\begin{array}{l}\text { Highest education attained by father } \\
\text { is primary school. }\end{array}$ & $\begin{array}{c}0.0994 \\
(0.0875)\end{array}$ & $\begin{array}{c}0.0889 \\
(0.1157)\end{array}$ & $\begin{array}{c}0.0920 \\
(0.1202)\end{array}$ \\
\hline $\begin{array}{l}\text { Highest education attained by father } \\
\text { is more than primary school. }\end{array}$ & $\begin{array}{l}-0.0053 \\
(0.0920)\end{array}$ & $\begin{array}{l}-0.0078 \\
(0.1126)\end{array}$ & $\begin{array}{l}-0.0187 \\
(0.1157)\end{array}$ \\
\hline Rural Residence & $\begin{array}{l}0.4486 * * * \\
(0.0986)\end{array}$ & $\begin{array}{l}0.4636 * * * \\
(0.1245)\end{array}$ & $\begin{array}{l}0.4264 * * * \\
(0.1285)\end{array}$ \\
\hline Asset Index & $\begin{array}{l}-0.1379 \\
(0.0887)\end{array}$ & $\begin{array}{l}-0.1461 \\
(0.1110)\end{array}$ & $\begin{array}{c}-0.1468 \\
(0.1137)\end{array}$ \\
\hline
\end{tabular}




\section{Table 3 continued}

\begin{tabular}{lccc}
\hline & \multicolumn{2}{c}{ Uncorrelated hazard estimates } & $\begin{array}{c}\text { Correlated hazard } \\
\text { estimates }\end{array}$ \\
& $(\mathbf{1})$ No heterogeneity & $\mathbf{( 2 )}$ with heterogeneity & (3) with heterogeneity \\
\hline \multirow{2}{*}{ No Toilet in House } & $(0.0734)$ & $(0.0837)$ & $(0.0857)$ \\
& $-0.2616 * *$ & $-0.2805 * *$ & $-0.2388 *$ \\
Piped Drinking Water & $(0.1043)$ & $(0.1389)$ & $(0.1446)$ \\
& 0.0101 & -0.0009 & -0.0150 \\
Piped Other Water & $(0.2341)$ & $(0.2797)$ & $(0.2836)$ \\
& -0.0103 & 0.0129 & 0.0295 \\
\hline Log-L & $(0.2357)$ & $(0.2806)$ & $(0.2832)$ \\
\hline
\end{tabular}

NOTE: Asymptotic standard errors in parentheses; Significance: '*'=10\%; '**'=5\%; '***'=1\%. 
Table 4: Structure of unobserved heterogeneity in the correlated hazard model

\begin{tabular}{lcc}
\hline & India & Pakistan \\
\hline Spacing $\sigma_{\mathrm{n}}^{2}$ & $0.2874 * * *$ & $0.3088 * * *$ \\
& $(0.0433)$ & $(0.0295)$ \\
Survival $\sigma_{\mathrm{s}}^{2}$ & $0.3557 *$ & $0.5926 * * *$ \\
& $(0.1753)$ & $(0.0758)$ \\
Correlation $\rho$ & $0.9793 *$ & $0.4957 * * *$ \\
& $(0.4569)$ & $(0.1495)$ \\
\hline
\end{tabular}

NOTE: Asymptotic standard errors in parentheses; Significance: ' $*$ '=10\%; '**'=5\%; '***'=1\%. 


\section{Table 5: Alternative child mortality estimates, India}

\begin{tabular}{|c|c|c|c|}
\hline & $\begin{array}{c}\text { Conditional Fixed } \\
\text { Effects Logit }\end{array}$ & $\begin{array}{c}\text { Random Effects } \\
\text { Probit }\end{array}$ & $\begin{array}{l}\text { Random-effects } \\
\text { Bivariate Probit }\end{array}$ \\
\hline Intercept & & $\begin{array}{l}-0.6880 \\
(0.7580)\end{array}$ & $\begin{array}{l}-0.6842 \\
(0.7985)\end{array}$ \\
\hline Boy & $\begin{array}{l}-0.0833 \\
(0.1224)\end{array}$ & $\begin{array}{l}-0.0328 \\
(0.0617)\end{array}$ & $\begin{array}{l}-0.0316 \\
(0.0628)\end{array}$ \\
\hline All sisters & & $\begin{array}{c}-0.2684 * * * \\
(0.0751)\end{array}$ & $\begin{array}{c}-0.2671 * * * \\
(0.0755)\end{array}$ \\
\hline Previous child dead & & $\begin{array}{c}0.4267 * * * \\
(0.0907)\end{array}$ & $\begin{array}{c}0.4230 * * * \\
(0.0923)\end{array}$ \\
\hline Prior spacing short (<15 m) & $\begin{array}{c}0.8736 * * * \\
(0.1475)\end{array}$ & $\begin{array}{l}0.3886 * * * \\
(0.0785)\end{array}$ & $\begin{array}{c}0.3621 * * * \\
(0.0864)\end{array}$ \\
\hline Posterior spacing short $(<15 \mathrm{~m})$ & $\begin{array}{c}1.1713^{* * *} \\
(0.1518)\end{array}$ & $\begin{array}{c}0.4806 * * * \\
(0.0805)\end{array}$ & $\begin{array}{c}0.4291 * * * \\
(0.1041)\end{array}$ \\
\hline Mother's age 21-25 years & $\begin{array}{l}-0.2674 \\
(0.2143)\end{array}$ & $\begin{array}{l}-0.0487 \\
(0.1397)\end{array}$ & $\begin{array}{l}-0.0597 \\
(0.1438)\end{array}$ \\
\hline Mother's age 26-30 years & $\begin{array}{c}-0.6525 * * * \\
(0.2332)\end{array}$ & $\begin{array}{c}0.0457 \\
(0.1436)\end{array}$ & $\begin{array}{l}0.0339 \\
0.1466)\end{array}$ \\
\hline Mother's age $>30$ years & $\begin{array}{c}-1.3320 * * * \\
(0.2848)\end{array}$ & $\begin{array}{l}-0.0760 \\
(0.1698)\end{array}$ & $\begin{array}{l}-0.0844 \\
(0.1735)\end{array}$ \\
\hline Father is literate & & $\begin{array}{c}0.0907 \\
(0.0769)\end{array}$ & $\begin{array}{c}0.0927 \\
(0.0785)\end{array}$ \\
\hline Mother has primary schooling & & $\begin{array}{c}0.0151 \\
(0.1063)\end{array}$ & $\begin{array}{c}0.0170 \\
(0.1086)\end{array}$ \\
\hline $\begin{array}{l}\text { Mother has middle/higher } \\
\text { schooling }\end{array}$ & & $\begin{array}{l}0.2308 * \\
(0.1210)\end{array}$ & $\begin{array}{l}0.2313 * \\
(0.1231)\end{array}$ \\
\hline Hindu & & $\begin{array}{c}0.0328 \\
(0.0726)\end{array}$ & $\begin{array}{c}0.0344 \\
(0.0732)\end{array}$ \\
\hline Muslim & & $\begin{array}{l}-0.1796 \\
(0.2155)\end{array}$ & $\begin{array}{l}-0.1763 \\
(0.2207)\end{array}$ \\
\hline Other religion & & $\begin{array}{c}0.2408 \\
(0.3079)\end{array}$ & $\begin{array}{c}0.2202 \\
(0.4654)\end{array}$ \\
\hline Composite asset index & & $\begin{array}{c}-0.2413 * * * \\
(0.0451)\end{array}$ & $\begin{array}{c}-0.2418 * * * \\
(0.0456)\end{array}$ \\
\hline Modern toilet & & $\begin{array}{l}-0.1256 \\
(0.0928)\end{array}$ & $\begin{array}{l}-0.1263 \\
(0.0937)\end{array}$ \\
\hline Safe drinking water & & $\begin{array}{l}-0.6062 \\
(0.7393)\end{array}$ & $\begin{array}{l}-0.5910 \\
(0.7792)\end{array}$ \\
\hline Rural & & $\begin{array}{c}0.0790 \\
(0.0954)\end{array}$ & $\begin{array}{c}0.0786 \\
(0.0964)\end{array}$ \\
\hline Born in the 1970s & & $\begin{array}{c}-0.2742 * * \\
(0.1229)\end{array}$ & $\begin{array}{c}-0.2791 * * \\
(0.1250)\end{array}$ \\
\hline Born in the 1980s & & $\begin{array}{c}-0.3324 * * * \\
(0.1261)\end{array}$ & $\begin{array}{c}-0.3348 * * * \\
(0.1278)\end{array}$ \\
\hline Born in the 1990s & & $\begin{array}{c}-0.4414 * * \\
(0.2027)\end{array}$ & $\begin{array}{c}-0.4462 * * \\
(0.2073)\end{array}$ \\
\hline
\end{tabular}




\begin{tabular}{lccc} 
Correlation & No & No & Yes \\
Log-L & -6424.420 & -1136.84 & -2436.20 \\
\hline
\end{tabular}

Asymptotic standard errors are shown below coefficient estimates.

Significance: ${ }^{\prime} * 10 \% ;^{\prime} * * '=5 \% ;{ }^{\prime} * * * '=1 \%$. 
Table 6: Alternative child mortality estimates, Pakistan

\begin{tabular}{|c|c|c|c|}
\hline & $\begin{array}{l}\text { Conditional Fixed } \\
\text { Effects Logit }\end{array}$ & $\begin{array}{c}\text { Random Effects } \\
\text { Probit }\end{array}$ & $\begin{array}{l}\text { Random-effects } \\
\text { Bivariate Probit }\end{array}$ \\
\hline Constant & & $\begin{array}{c}-1.1387 * * * \\
(0.1298)\end{array}$ & $\begin{array}{c}-1.1298 * * * \\
(0.1289)\end{array}$ \\
\hline Boy & $\begin{array}{l}-0.0998 \\
(0.1019)\end{array}$ & $\begin{array}{l}-0.0394 \\
(0.0466)\end{array}$ & $\begin{array}{l}-0.0417 \\
(0.0485)\end{array}$ \\
\hline Posterior Spacing Short $(<15 \mathrm{~m})$ & $\begin{array}{c}0.6677 * * * \\
(0.1224)\end{array}$ & $\begin{array}{c}0.4967 * * * \\
(0.0549)\end{array}$ & $\begin{array}{c}0.3453 * * * \\
(0.0591)\end{array}$ \\
\hline Prior Spacing Short $(<15 \mathrm{~m})$ & $\begin{array}{c}0.8319 * * * \\
(0.1209)\end{array}$ & $\begin{array}{c}0.3569 * * * \\
(0.0539)\end{array}$ & $\begin{array}{l}0.4778 * * * \\
(0.0616)\end{array}$ \\
\hline Any previous child dead & $\begin{array}{c}-1.5954 * * * \\
(0.1634)\end{array}$ & $\begin{array}{c}0.4218 * * * \\
(0.0547)\end{array}$ & $\begin{array}{l}0.4187 * * * \\
(0.0568)\end{array}$ \\
\hline Mother's age: $21-25$ & $\begin{array}{c}0.0833 \\
(0.1748)\end{array}$ & $\begin{array}{c}-0.1688 * * \\
(0.0672)\end{array}$ & $\begin{array}{c}-0.1699 * * \\
(0.0661)\end{array}$ \\
\hline Mother's age: $26-30$ & $\begin{array}{c}0.1024 \\
(0.2129)\end{array}$ & $\begin{array}{c}-0.2910 * * * \\
(0.0759)\end{array}$ & $\begin{array}{c}-0.2922 * * * \\
(0.0757)\end{array}$ \\
\hline Mother's age: $>30$ & $\begin{array}{l}-0.9464 \\
(0.6195)\end{array}$ & $\begin{array}{c}-0.6019 * * * \\
(0.1425)\end{array}$ & $\begin{array}{l}-0.6078 * * * \\
(0.1452)\end{array}$ \\
\hline Father's age: $26-30$ & $\begin{array}{l}-1.2153 * * \\
(0.5906)\end{array}$ & $\begin{array}{c}-0.2611 * * \\
(0.1146)\end{array}$ & $\begin{array}{c}-0.2629 * * \\
(0.1181)\end{array}$ \\
\hline Father's age: $31-35$ & $\begin{array}{l}-0.1542 \\
(0.2249)\end{array}$ & $\begin{array}{l}-0.0239 \\
(0.0755)\end{array}$ & $\begin{array}{l}-0.0240 \\
(0.0770)\end{array}$ \\
\hline Father's age: $>36$ & $\begin{array}{c}0.0727 \\
(0.2259)\end{array}$ & $\begin{array}{c}0.0105 \\
(0.0634)\end{array}$ & $\begin{array}{c}0.0126 \\
(0.0645)\end{array}$ \\
\hline $\begin{array}{l}\text { Highest education attained by mother } \\
\text { is primary school }\end{array}$ & & $\begin{array}{l}-0.1775^{*} \\
(0.0990)\end{array}$ & $\begin{array}{c}-0.1847 * \\
(0.1036)\end{array}$ \\
\hline $\begin{array}{l}\text { Highest education attained by mother } \\
\text { is more than primary school. }\end{array}$ & & $\begin{array}{c}-0.2936 * * * \\
(0.1061)\end{array}$ & $\begin{array}{c}-0.3000 * * * \\
(0.1132)\end{array}$ \\
\hline $\begin{array}{l}\text { Highest education attained by father is } \\
\text { primary school. }\end{array}$ & & $\begin{array}{c}0.0500 \\
(0.0739)\end{array}$ & $\begin{array}{c}0.0495 \\
(0.0773)\end{array}$ \\
\hline $\begin{array}{l}\text { Highest education attained by father is } \\
\text { more than primary }\end{array}$ & & $\begin{array}{c}0.0038 \\
(0.0699)\end{array}$ & $\begin{array}{c}0.0040 \\
(0.0771)\end{array}$ \\
\hline Rural Residence & & $\begin{array}{l}0.2265 * * * \\
(0.0836)\end{array}$ & $\begin{array}{l}0.2283 * * * \\
(0.0857)\end{array}$ \\
\hline Asset Index & & $\begin{array}{l}-0.0776 \\
(0.0664)\end{array}$ & $\begin{array}{l}-0.0762 \\
(0.0725)\end{array}$ \\
\hline year_b77 & & $\begin{array}{l}0.1597 * * * \\
(0.0557)\end{array}$ & $\begin{array}{l}0.1611 * * * \\
(0.0582)\end{array}$ \\
\hline No Toilet in House & & $\begin{array}{l}-0.0618 \\
(0.0950)\end{array}$ & $\begin{array}{l}-0.0635 \\
(0.0909)\end{array}$ \\
\hline Piped Drinking Water & & $\begin{array}{l}-0.1674 \\
(0.1633)\end{array}$ & $\begin{array}{l}-0.1813 \\
(0.1827)\end{array}$ \\
\hline Piped Other Water & & $\begin{array}{c}0.1304 \\
(0.1680)\end{array}$ & $\begin{array}{c}0.1432 \\
(0.1816)\end{array}$ \\
\hline $\begin{array}{l}\text { Correlation } \\
\text { Heterogeneity } \\
\text { Log-L }\end{array}$ & $\begin{array}{c}\text { No } \\
\text { No } \\
-775.3024\end{array}$ & $\begin{array}{c}\text { No } \\
\text { Yes } \\
-2006.8755\end{array}$ & $\begin{array}{c}\text { Yes } \\
\text { Yes } \\
-4549.64\end{array}$ \\
\hline
\end{tabular}


Table 7: A comparison of Correlated hazard and bivariate probit estimates

\begin{tabular}{|c|c|c|c|}
\hline & Correlated hazard & Bivariate probit & LR statistics \\
\hline & Log-L1 & Log-L2 & $2(\operatorname{logL} 2-\log \mathrm{L} 1)$ \\
\hline Pakistani Punjab & -27718.14 & -4549.64 & $46337 * * *$ \\
\hline Indian Punjab & -14124.2 & -4800.49 & $18647.42 * * *$ \\
\hline
\end{tabular}


Table 8: Reverse Correlated Hazard. The effect of Child Mortality on the Time to Next Birth

\begin{tabular}{lcc}
\hline & India & Pakistan \\
\hline SURV & $-0.0065 * * *$ & 0.0001 \\
& $(0.0012)$ & $(0.0003)$ \\
Survival $\sigma_{\mathrm{s}}{ }^{2}$ & $0.4358 * * *$ & $0.5858 * * *$ \\
& $(0.1633)$ & $(0.0731)$ \\
Spacing $\sigma_{\mathrm{n}}{ }^{2}$ & $0.3266 * * *$ & $0.3109 * * *$ \\
& $(0.0403)$ & $(0.0301)$ \\
\hline Correlation $\rho$ & $0.5640 *$ & $0.7166 * * *$ \\
& $(0.3185)$ & $(0.1434)$ \\
\hline Log-L & -14563.62 & -28003.47 \\
\hline
\end{tabular}

NOTE: Asymptotic standard errors in parentheses;

Significance: ' $*$ ' $=10 \% ; '$ ' $^{\prime} *$ '=5\%; '***'=1\%.

Regressions control for other household and child specific characteristics. See text for details 
Table 9: Effects of breastfeeding on spacing and child mortality

\begin{tabular}{|c|c|c|c|c|}
\hline & \multicolumn{2}{|c|}{ India } & \multicolumn{2}{|c|}{ Pakistan } \\
\hline & Spacing & Survival & Spacing & Survival \\
\hline Ever Breastfed & $\begin{array}{c}0.1188 \\
(0.1571)\end{array}$ & $\begin{array}{l}-0.5608 * * \\
(0.2354)\end{array}$ & & \\
\hline $\begin{array}{l}\text { Duration of } \\
\text { Breastfeeding }\end{array}$ & & & $\begin{array}{c}-0.0627 * * * \\
(0.0061)\end{array}$ & $\begin{array}{c}-0.4639 * * * \\
(0.0342)\end{array}$ \\
\hline Spacing $\sigma_{n}^{2}$ & \multicolumn{2}{|c|}{$\begin{array}{c}0.2879 * * * \\
(0.0444)\end{array}$} & \multicolumn{2}{|c|}{$\begin{array}{c}0.8115 * * * \\
(0.1133)\end{array}$} \\
\hline Survival $\sigma_{\bar{\omega} \mathrm{s}}^{2}$ & \multicolumn{2}{|c|}{$0.3330 * *$} & \multicolumn{2}{|c|}{$\begin{array}{l}2.3208 * * * \\
(0.2818)\end{array}$} \\
\hline Correlation $\rho$ & \multicolumn{2}{|c|}{$\begin{array}{r}0.5260 * * \\
(0.2015) \\
\end{array}$} & \multicolumn{2}{|c|}{$0.6209 * * *$} \\
\hline Log-L & \multicolumn{2}{|c|}{-14145.9} & \multicolumn{2}{|c|}{-3438.2403} \\
\hline
\end{tabular}

NOTE: Asymptotic standard errors in parentheses; $\quad$ Significance: ' $*$ ' $=10 \%$; ' $* * '=5 \%$; ' $* * * '=1 \%$.

Note that the breastfeeding variable is a binary one for the Indian sample, indicating whether the child has ever been breastfed. For the Pakistan sample however it denotes the duration of breastfeeding in months. Because of lack of heterogeneity in the Indian sample, we could not get uniform results for the two samples. Regressions control for other household and child specific characteristics as in Tables 2 and 3 respectively for India and Pakistan. 
Figure 1: Smoothed Hazard Estimates of Duration to Next Birth (NEXT)

Pakistan

Duration to Next Birth

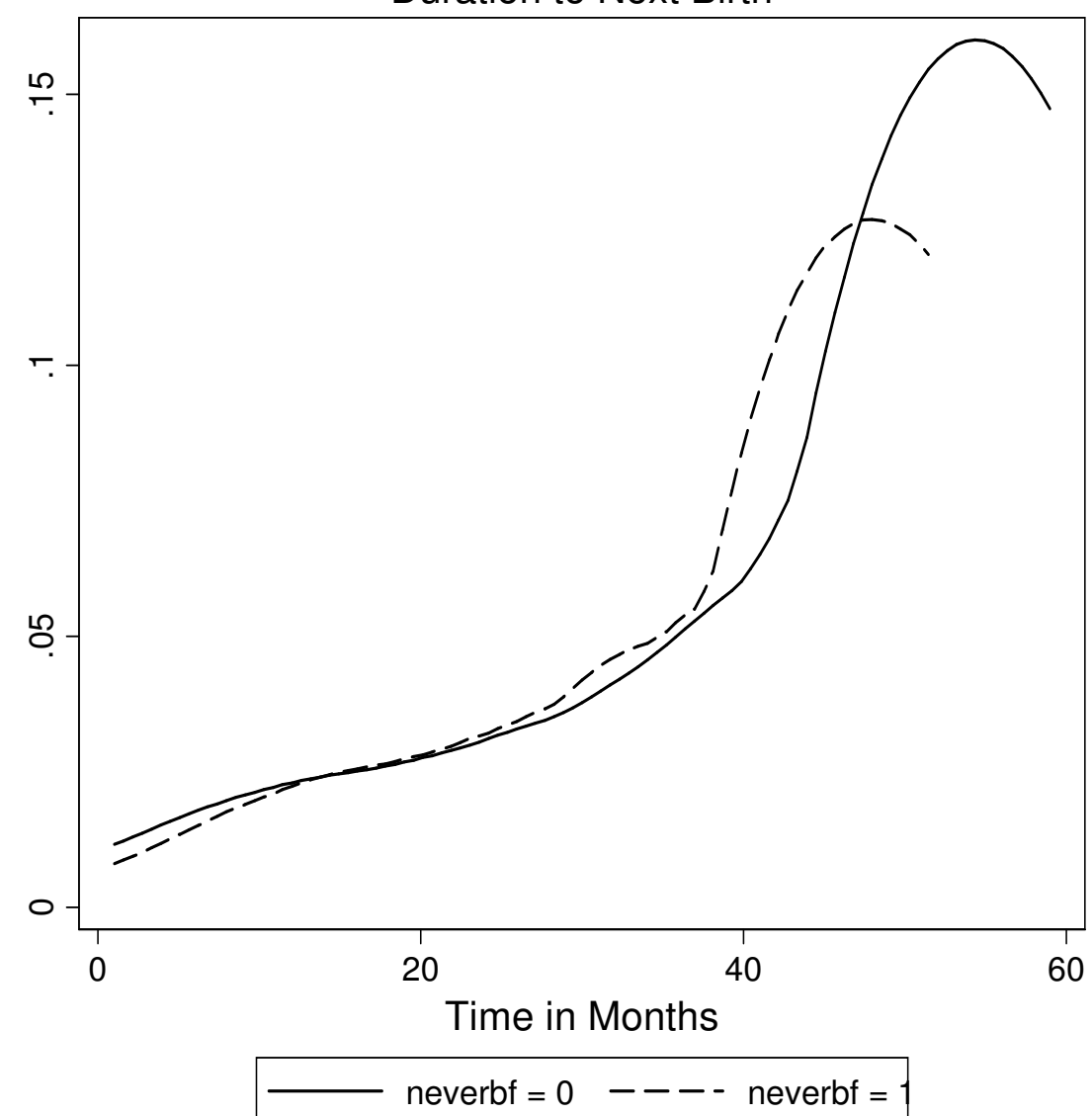

India

Duration to Next Birth

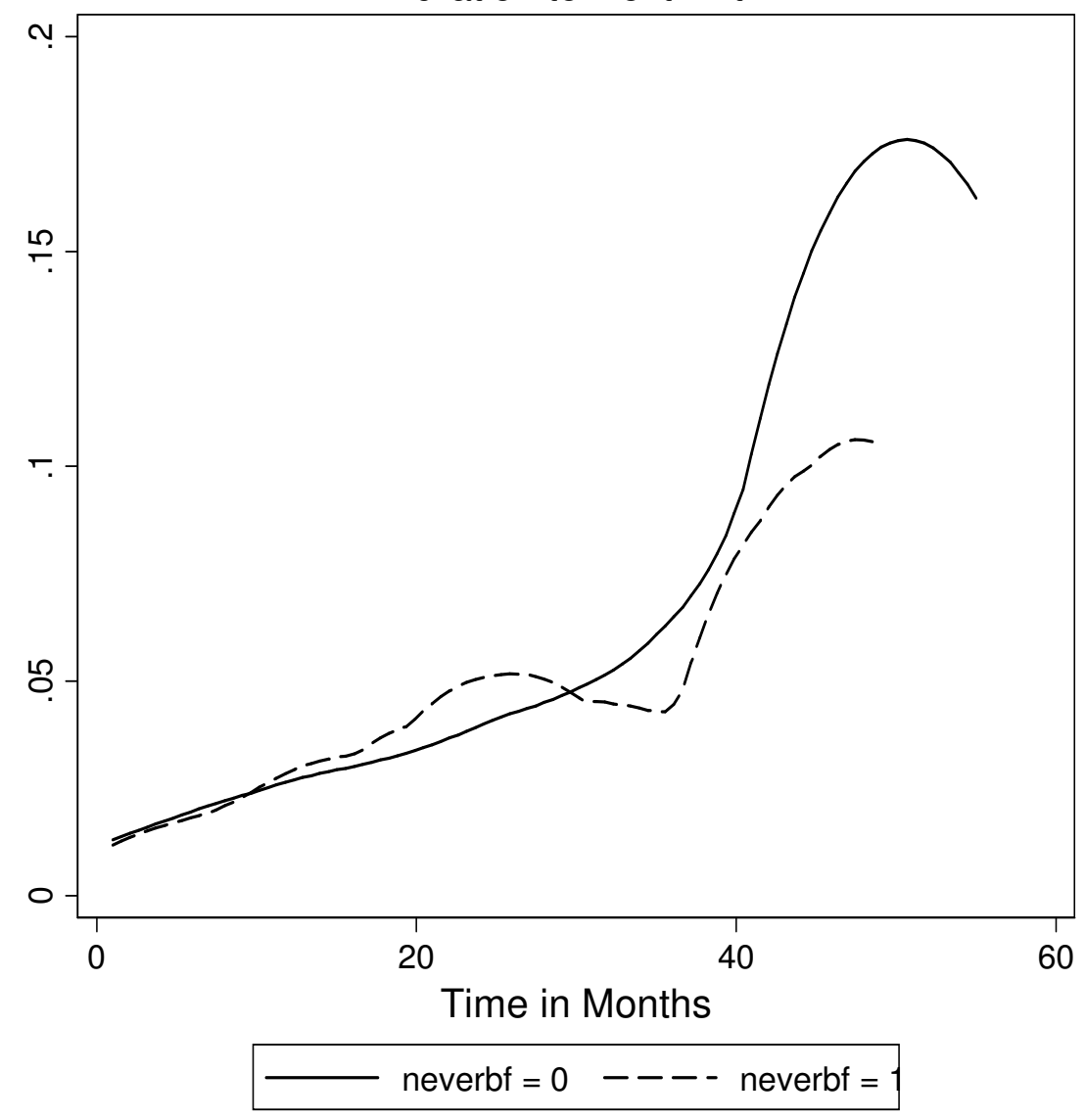


Figure 2: Smoothed Hazard Estimates of Child Survival (SURV)

Pakistan

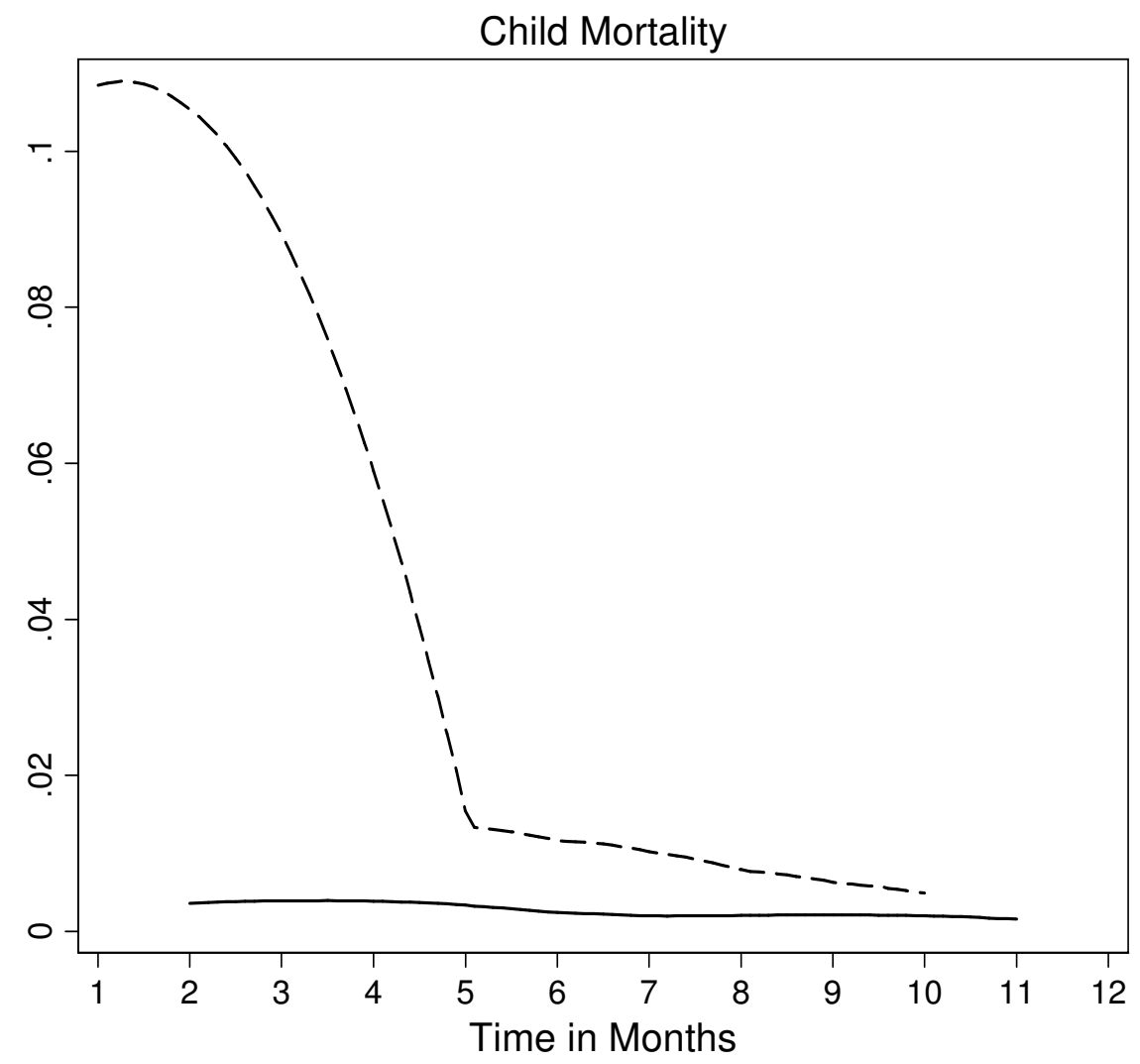

neverbf $=0 \quad----$ neverbf $=1$
India

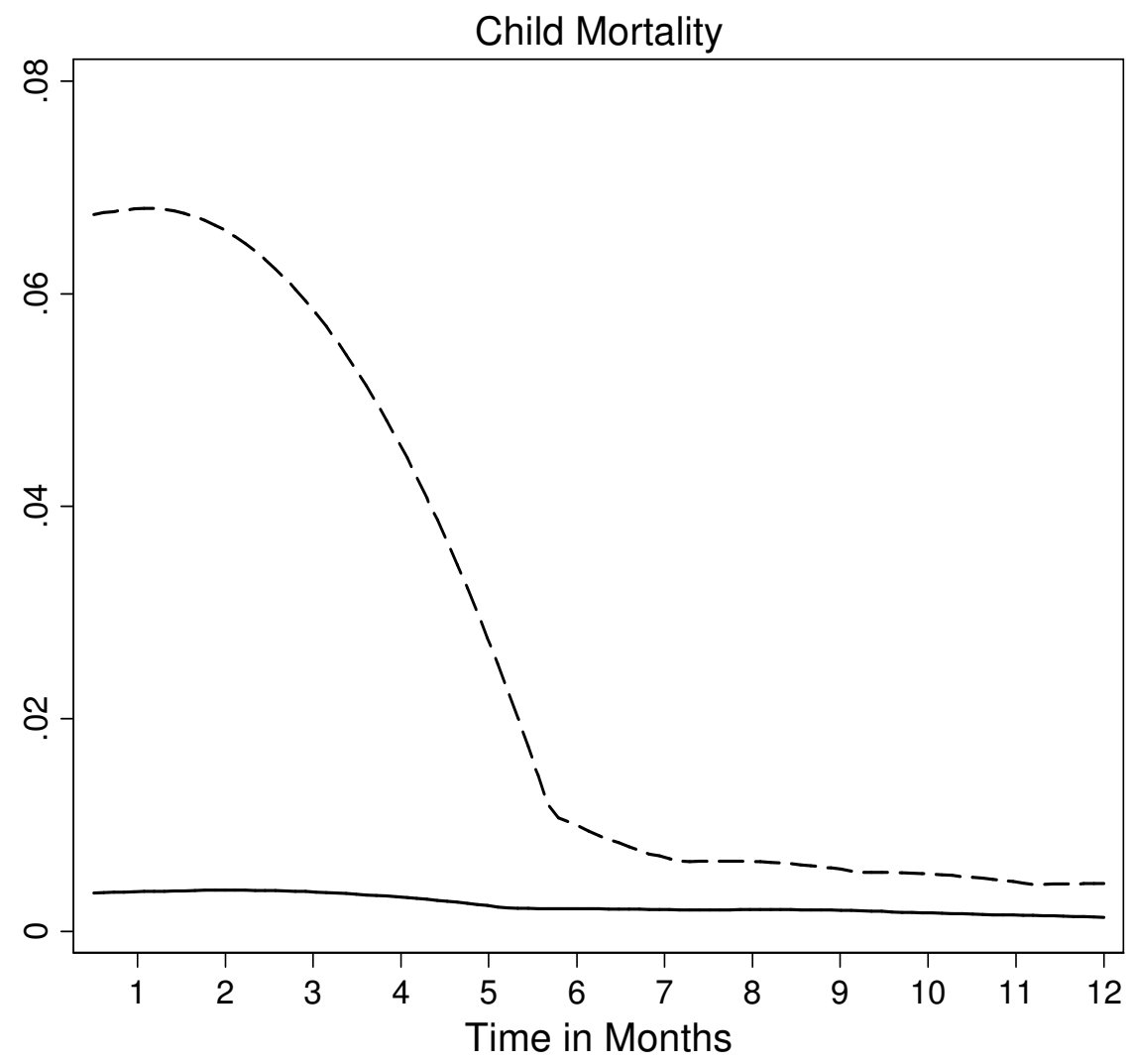

neverbf $=0$ 